\title{
O Homem Novo nas Literaturas Africanas em Língua Portuguesa pré-independência
}

The New Man in the Pre-Independence Lusophone African Literature

\author{
Solange Evangelista Luís*
}

Palavras-chave:

Homem Novo

Literaturas Africanas

em Língua Portuguesa

Guerrilheiro

Keywords:

New Man

Lusophone African Literature Guerrilla fighter
Resumo: Este ensaio irá analisar as características basilares do conceito de Homem Novo, desde o surgimento do Homem Soviético, até à década de 60 e perceber como estas particularidades são utilizadas na Poesia de Combate das literaturas africanas em língua portuguesa, no contexto da luta armada de libertação. Para o efeito foi selecionada a primeira antologia dedicada à Poesia de Combate, publicada no mundo lusófono, a antologia do angolano Mário de Andrade Antologia Temática de Poesia Africana II: O Canto Armado. Embora a designação 'Homem Novo' nunca tenha sido utilizada por Andrade no prefácio por ele escrito para esta antologia, a análise temática e ideológica, assim como o tratamento poético dado ao guerrilheiro indicam que foi criado para ser o Homem Novo da revolução dos países africanos de língua portuguesa.

\begin{abstract}
This essay will explore the basic characteristics of the New Man concept, from its emergence as the Soviet Man to its use in the 60s, while understanding how these features are assimilated into Combat Poetry of African literature written in Portuguese, in the context of the armed struggle for liberation. The work of the Angolan anthologist Mário de Andrade, Antologia Temática de Poesia Africana II: O Canto Armado, the first dedicated to Combat Poetry published in the lusophone world, will be discussed in this essay. Although the designation 'New Man' is never used by Andrade in the preface written for his anthology, a closer thematic and ideological analysis, as well as the observance of the poetic treatment given to the guerrilla fighter in this poetry, indicate that he is conceived to be the New Man of the Portuguese-speaking African revolution.
\end{abstract}

Recebido em 14 de maio de 2020. Aprovado em 27 de outubro de 2020.
Por toda a parte, entre a morte e a vida, no derramar belo do vermelho sangue ela se alastrava, viva, majestosa, esta chama quão formosa como o amor, quão bela como o desejo, dominando o gesto, o olhar e a vida. Kwame Kondé "Revolução"'

Este ensaio pretende compreender como o conceito de Homem Novo é utilizado nos 97 poemas reunidos na Antologia Temática de Poesia Africana II: O Canto Armado, organizada pelo angolano
Mário Pinto de Andrade e primeiro publicada em 1979. Serão observadas as temáticas dos poemas desta coletânea, assim como o tratamento dado à figura do guerrilheiro que luta pela independência das então colônias portuguesas em África, a fim de perceber como são dadas as vestes de Homem Novo da revolução libertária das nações africanas de língua portuguesa a este guerrilheiro africano.

Segundo Yinghong Cheng, no seu livro Creating the "New Man": from Enlightenment Ideals to Socialist Realities, o conceito de Homem Novo

\footnotetext{
* Professora permanente dos Programas de Graduação e Pós-Graduação em Ensino da Língua Portuguesa do Instituto Superior de Ciências da Educação (ISCED) da Huíla, em Lubango, Angola; professora convidada do Programa de Pós-Graduação em Ensino da História de África (Departamento de Ciências Sociais do ISCED-Huíla). Doutora pela Universidade de Coimbra, Portugal, em Literaturas dos Países Africanos de Língua Oficial Portuguesa e Mestre pela Universidade de York, Toronto, em Teoria Pós-Colonial. E-mail: luissolange@hotmail.com.
} 
surge na Rússia, por volta de 1860 , com a criação do Homem Soviético: moral e psicologicamente superior. O Homem Soviético foi o primeiro Homem Novo na história da humanidade, um "modelo humano alternativo"2 (CHENG, 2009, p. 3) que foi sofrendo alterações ao longo da sua existência ideológica. Segundo Cheng, o conceito de Homem Novo é embasado e inspirado nas ideias Iluministas que depreendem a natureza humana como o resultado do ambiente que a envolve, altera e molda. Nesta senda de ideias, o conceito de Homem Novo tem como objetivo transformar a identidade e construir o carácter (CHENG, 2009, p. 190).

O regime soviético foi o primeiro governo a tentar implementar a engenharia social numa escala nacional, com embasamento nas experiências de Pavlov na área da psicologia do comportamento sobre o condicionamento e o reflexo condicionado. O objetivo primordial soviético era a formação ideológica que, pensavam, levaria o indivíduo a dedicar-se à ação política.

Mais tarde este conceito é apropriado pela China e por Cuba, casos discutidos com profundidade por Cheng, assim como por países recém-descolonizados que procuravam, entre outros desígnios, construir uma nova identidade nacional e criar um sentimento de pertença à nova comunidade que se ergue (CHENG, 2009, p.208). O conceito é assim adaptado às necessidades de cada contexto onde é implementado, desenvolvendo traços inerentes às circunstâncias ideológicas e socioeconómicas particulares a estes espaços, enquanto mantêm características políticas e comportamentais basilares, que se tornam transversais a estes diferentes contextos (CHENG, 2009, p. 220). Assim sendo, a título exemplar, tanto o Homem Novo soviético como o chinês e o cubano, apesar das suas especificidades, apresentam características transversais: o Homem Novo está imbuído do espírito de sacrifício, abnegação e altruísmo, enquanto apresenta conformidade ideológica e lealdade ao Partido (CHENG, 2009, p. 220).

Ao traçar a história do surgimento do Homem Novo, Cheng discute o papel da literatura na disseminação deste arquétipo para consolidar parâmetros ideológicos e comportamentais. Cheng atribuiao filósofo eescritor russo Nikolay Gavrilovich Chernyshevsky a primeira ficção narrativa que deu corpo ao conceito de Homem Novo. Que Fazer? de 1861, tem como protagonista Rakhmetov, cujos atributos heróicos e a autodesignada missão de liberar o povo serviram de inspiração para gerações soviéticas vindouras, influenciando pessoas como Vladimir Lenin (CHENG, 2009, p. 20).

$\mathrm{O}$ guerrilheiro, na Poesia de Combate africana em língua portuguesa, consciente da sua condição de colonizado, assume, assim como Rakhmetov (o herói de Chernyshevsky), a missão heroica de libertar o seu povo. Uma missão revolucionária imbuída de sacrifício pelo bem coletivo. Este ensaio observará o tratamento dado ao conceito de Homem Novo na Antologia Temática de Poesia Africana II: O Canto Armado, a primeira antologia de Poesia de Combate no espaço lusófono. Embora esta antologia tenha sido organizada por Andrade em 1979 (depois da independência de todas as colônias portuguesas), reúne poemas que remetem para os anos de luta armada: do início da década de 60 até início da década de 70 do século passado. Este antólogo e estudioso das literaturas africanas, entende que a poesia africana foi sempre uma espécie canto armado, continuamente combativa por fazer parte de uma "tradição literária de resistência” (ANDRADE, 1980, p. 3). Nesta antologia Andrade reúne aquela que é comumente referida como Poesia de Combate, escrita no decorrer da luta de libertação das então colónias portuguesas, em território já libertado e entendida por Franz Fanon como poesia da "fase da luta" (FANON, 1963, p. 222). Poesia escrita por e para guerrilheiros, para inspirar outros Homens Novos da África de língua portuguesa a se comprometerem com a ação política.

A Poesia de Combate cria um modelo de Homem Novo adaptado ao contexto daquela época: o do guerrilheiro africano combatendo pela liberdade do seu povo, o "herói libertador" (ANDRADE, 1980, p. 6).

Cheng atribui ao Iluminismo a origem do conceito de Homem Novo5. A convição na maleabilidade e no aperfeiçoamento da natureza 
humana mediante a maneira com que esta responde ao ambiente em que se insere, levaram ao surgimento do Behaviorismo e do Determinismo Geográfico, que serviram de base para o conceito de Homem Novo. A concepção de John Locke da mente como um mecanismo que pode ser remodelado através da manipulação das circunstâncias que a envolve, exemplifica o pensamento iluminista de que a natureza humana pode ser moldada e mudada de acordo com o ambiente onde se encontra (CHENG, 2009, p. 8). Carl Marx apresenta também uma visão determinista da natureza humana quando afirma que os meios de produção determinam os processos sociais, políticos e espirituais da vida. Para Marx, "[n]ão é a consciência do homem que determina a sua existência, mas, pelo contrário, a sua existência social determina a sua consciência" ${ }^{\text {(Marx apud }}$ CHENG, 2009, p. 13) ${ }^{7}$.

Segundo Cheng, o termo Homem Novo entrou para o léxico político por volta de 1860 em associação com a Intelligentsia russa, um grupo revolucionário composto por intelectuais associados à ideia de "socialismo", de tal forma comprometidos com a sua causa ao ponto de compreenderem a suas vidas como veículos para a concretização de uma sociedade ideal (CHENG, 2009, p. 15-16). Esta ideia pode ser melhor ilustrada pelas palavras de Vissarion Grigoryevich Belisnsky sobre a revolução: "Tudo a partir dela, para ela, e em direção a ela"8 (Apud CHENG, 2009, p. 16). É neste contexto que a ideia de Homem Novo é engendrada e disseminada na literatura russa, com destaque para a publicação, em 1861, da novela Que Fazer? de Chernyshevsky, cujo protagonista, Rakhmetov, representa a ambição de uma nova geração revolucionária, fundindo a "ideologia na personalidade, transformando um indivíduo em um homem novo"9 (CHENG, 2009, p. 17), tornando assim Rakhmetov no primeiro modelo de Homem Novo, dando o termo a conhecer mais amplamente. Durante a era soviética este livro foi recomendado como um dos mais importantes da literatura russa do século XIX, sendo igualmente traduzido para as diversas línguas do bloco socialista (Ibidem), influenciando e inspirando futuras gerações ${ }^{10}$.
A Rakhmetov Chernyshevsky se atribuiu aqueles que viriam a ser os atributos basilares do Homem Novo. Entre outros, Cheng chama a atenção para a rejeição, na novela, de qualquer afeição humana que não estivesse associada ao interesse político comum, com especial destaque para a sexualidade, notando a "incompatibilidade entre a sexualidade e o compromisso político"11 (CHENG, 2009, p. 17), uma vez que o desejo sexual é tido como uma potencial distração daquilo que é a missão e o comprometimento com a causa libertária. O Homem Novo de Chernyshevsky, ao rejeitar o seu impulso primordial sexual, pratica a abnegação (Ibidem), que viria a ser um dos atributos essenciais deste novo tipo de ser humano, encontrado também em outras versões deste arquétipo. Cheng nota que, durante a Revolução Cultural Chinesa, a abnegação da sexualidade fez-se notar na completa omissão de relacionamentos sexuais na literatura revolucionária, onde os "personagens heróicos pareceiam assexuados"12 (Ibidem). A sexualidade é entendida, na literatura revolucionária comunista, de uma forma generalizada e transversal a diferentes contextos, como uma distração indesejada para o Homem Novo (CHENG, 2009, p. 38).

A nota de abertura da obra de Sergey Nechayev, The Revolutionary Catechism, de 1869, melhor transparece a abnegação como essência basilar do Homem Novo:

O revolucionário é um homem condenado. Ele não tem interesses próprios, nem casos, nem sentimentos, nem apegos, nem pertences, nem mesmo um nome. Tudo nele é absorvido por um único interesse exclusivo, um único pensamento, uma única paixão - a revolução ${ }^{13}$. (Apud CHENG, 2009, p. 18)

O Homem novo é um homem 'condenado' à abnegação, este é o preço da revolução. As palavras de Nechayev encontram eco nas de Che Guevara, um século mais tarde, quando diz que "[n]ão há vida fora da revolução"14 (Apud CHENG, 2009, p. 19), tornando-se ele próprio num modelo de Homem Novo a ser seguido. Esta ideia ecoa as palavras do lema da revolução cubana: "que todos se tornem Che"15 (CHENG, 2009, p. 188). 
Segundo Cheng, o Homem Novo Soviético servia como um modelo a ser emulado, encorporando ideiais e padrões. Algumas das características deste Homem Novo, segundo Cheng, eram: a abnegação, a consciência de classe, a consciência política, a fé na revolução e a rejeição do conforto pessoal ${ }^{16}$ (CHENG, 2009, p. 33), assim como o seu sentido de propósito e a sua moralidade superior ${ }^{17}$ (CHENG, 2009, p. 202).

Conforme atribuído a Rakhmetov, o primeiro Homem Novo na literatura, Andrei Sinyavsky aponta o heroísmo como característica fundamental do Homem Novo Soviético, sem a qual ele não teria razão de ser. Segundo este escritor russo, este heroísmo rege-se por três virtudes cardeais, que refletem aquelas citadas por Cheng:

uma fé fanática no objetivo supremo; a capacidade de traduzir essa fé em ação; e um desejo de lutar não pela própria glória, mas pelo bem geral. Idealmente, esses feitos heróicos não deveriam ter proporcionado ao homem novo qualquer sucesso pessoal ou lucro e o mesmo deveria permanecer anónimo. ${ }^{18}$ (SINYAVSKY, 1990, p. 117)

Ao longo do tempo, o conceito de Homem Novo vai se transformando para melhor se adaptar às exigências contextuais ${ }^{19}$, contudo mantém sempre o heroicismo, apontado por Sinyavsky, como sua raison d'être. Mas é o seu sentido de propósito, de missão, que o torna tão atraente para intelectuais, activistas e até mesmo homens do clero ocidentais (CHENG, 2009, p. 195). Entre 1920 e 1930, na Europa dilacerada pela guerra, social e culturalmente desorientada, a experiência comunista soviética era observada com reservas, mas também com entusiasmo. A crise económica e política de 1930 torna a experiência comunista de coletividade e solidariedade atraente para os ocidentais, desiludidos com o materialismo e com aquilo que entendiam ser o vazio espiritual das suas sociedades. O Homem Novo torna-se assim na contraposição ao homem espiritualmente vazio, estragado pelo egoísmo e pelo conforto material (CHENG, 2009, p. 195).
Para os líderes das nações emergentes no século XIX, procurando erguer seus países, depois de longas lutas de libertação para descolonização e independência, o conceito de Homem Novo, baseado na transformação da identidade e na construção do carácter, apresenta-se promissor (CHENG, 2009, p. 190). A construção de uma nova identidade e do sentimento de pertença à nova nação são algumas das preocupações dos dirigentes destes novos países. Eles olham para os líderes dos países comunistas que, mobilizaram a sua população (seu mais precioso recurso) e conseguiram construir e modernizar seus países. Esta população modelo colabora "suprimindo e até mesmo abnegando as suas necessidades materiais e interesses individuais para que o Estado pudesse controlar quantos recursos precisasse para o seu desenvolvimento"20 (CHENG, 2009, p. 208), actuando dentro daquilo que é esperado de uma população de Homens Novos. O carácter essencial de abnegação do Homem Novo comunista, a sua solidariedade e o seu propósito comunitário, aliados à ideia de unificação da sociedade e de derrube das barreiras sociais que as separavam antes da revolução, fazem do comunismo e do conceito de Homem Novo alternativas atraentes por serem avessas ao sistema colonial, profundamente enraizado na hierarquização social e na exploração.

À medida que o estalinismo vai perdendo a sua atratividade, Cheng demonstra como os exemplos da China e de Cuba recebem especial atenção, principalmente pela sua capacidade de ganhar reconhecimento internacional, apesar da falta de colaboração e apoio do Ocidente. Essas são algumas das razões, entre outras (que não serão aqui discutidas ${ }^{21}$ ), que levam os movimentos de libertação africanos das antigas colónias portuguesas a escolherem o comunismo como sistema alternativo ao capitalismo. O Homem Novo comunista era especialmente atrativo pois marcava "uma transformação da mentalidade e atitude das pessoas"22 (CHENG, 2009, p. 208), uma profunda mudança de paradigma que reformulava a relação entre o índivíduo e a sociedade. No contexto das literaturas africanas em língua portuguesa, o Homem Novo, desenvolvido na Poesia de 
Combate, é o incansável guerrilheiro - o modelo do colonizado que deixa de ser vítima de um sistema que o anula, para ser agente fervoroso e dedicado de irradicação desse sistema. Ele é o colonizado remodelado: consciente da necessidade de servir fielmente o Partido que libertará a nação, passando assim a motor da sua própria história.

Mário de Andrade, no prefácio para a Antologia Temática de Poesia Africana II: O Canto Armado, argumenta pelo carácter combativo da poesia africana, quer nos cantos tradicionais que denunciam e celebram a resistência contra a ocupação europeia, como na poesia moderna de resistência ao colonialismo. Para este estudioso da literatura africana, "a memória colectiva dos povos africanos gravou e repercutiu, ao longo das gerações, os ecos poéticos das primeiras formas de violência contra o equilíbrio social e comunitário" (ANDRADE, 1980, p. 3). A tradição literária africana carrega a história da resistência africana, o que torna difícil "datar com exactidão o nascimento da poesia africana de combate"13 (Ibidem). A seleção poética desta antologia reflecte aquilo que Franz Fanon referiu como "poesia de revolta" ${ }^{44}$ (FANON, 1963, p. 226), escrita na fase da luta armada:

Durante esta fase, muitos homens e mulheres que até então nunca teriam pensado em produzir uma obra literária, agora que se encontram em circunstâncias excecionais - na prisão, com os Maquis, ou na véspera da sua execução - sentem a necessidade de falar para a sua nação, de compor a frase que expressa o coração do povo, e de se tornarem o porta-voz de uma nova realidade em ação. ${ }^{25}$ (FANON, 1963, p. 223)

Os poemas compilados por Andrade são poemas de luta, que apresentam uma poesia que "traz o testemunho vivo desse combate" (ANDRADE, 1980, p. 4), onde está patente “a figura do poeta-militante" (ANDRADE, 1980, p. 7). São poemas que, segundo este antólogo, "contêm uma projecção do ideal revolucionário" (Ibidem) e projetam "um apelo à mobilização muscular para a luta, se não à tomada das armas" (Ibidem). Esta poesia, de "linguagem clara e directa"(ANDRADE,
1980, p. 8), encontra receptividade naqueles que a lêem ou ouvem ${ }^{26}$, uma vez que "[o]s homens então colonizados reconhecem nos poemas os próprios fundamentos da sua situação, entendem os mecanismos da exploração colonial e encontram as motivações para a revolta" (ANDRADE, 1908, p. 7). Esta poesia revela a "figura do poeta-militante [que] afirma a sua personalidade e afina as suas armas, durante a guerra de libertação" (ANDRADE, 1980, p. 11). Esta guerra, para Andrade, pode ser assumida pelo poeta presencialmente ou pode ser "apenas um tema de inspiração" (Ibidem).

Esta é um poesia que pretende consciencializar, desalienar o homem colonizado para que este possa se elevar à condição de Homem Novo. Conforme revela Andrade, esta poesia foi produzida também por jovens guerrilheiros com fraca formação intelectual e literária, com um "conhecimento impreciso da linguagem, [e] insuficiente domínio de um idioma segundo" (ANDRADE, 1080, p. 11), o que a deixa "na fronteira da poesia" (ANDRADE, 1980, p. 9). Mas nota "o apelo íntimo, a necessidade de comunicar o justo, o prático, [e] o belo", uma vez que a revolução é compreendida como um ato de amor pela nação e de fraternidade, dado o seu teor libertário.

Um dos temas centrais desta poesia, segundo Andrade, é "o tema do herói libertador" (ANDRADE, 1980, p. 6), sendo o guerrilheiro aquele que liberta e o Partido o "portador das armas de libertação" (ANDRADE, 1980, p. 9). "Confiança no Partido, certeza na libertação, vitória do poder das armas" (Ibidem) são algumas das ideias chave identificadas por Andrade nesta poesia. Outras palavras encontradas repetidas vezes, durante a leitura dos poemas compilados, mostram a linguagem aguerrida da luta de libertação: coragem, sacrifício, liberdade, livre, esperança, missão, revolução, camarada, guerrilheiro, independente/ independência, vitória, combate, luta, sangue, matança/massacre. Outras palavras igualmente utilizadas, com menor ocorrência são: marcha, tiro, bala, munição, granadas, soldados, comandante, espinguarda, armas, cartucho, marchar, Capitão, tanques blindados, minas, fogo, gatilho, tortura, faca, angústia, inimigo e guerreiros. Estas palavras 
de teor belicista que rodeia o guerrelheiro apresentam-se como um novo léxico na poesia das literaturas africanas em língua portuguesa préindependência. Mas vale a pena ressaltar que esta poesia também apresenta palavras como esperança, sol, flores, primavera, construir, dia, liberdade, coração, jovem, comunidade, felicidade e amor, uma vez que a luta é percebida como um ato de criação e não de destruição. Trata-se da criação de algo novo, pela mão do Homem Novo na Poesia de Combate: o guerrilheiro.

As ideias chave apresentadas por Andrade: a do herói libertador que pertence a um Partido no qual deposita a sua total confiança, ressoam aquelas que são as características do Homem Novo comunista, conforme apresentadas por Cheng e Sinyavsky. O heroísmo (na acção altruísta, sem busca da glória pessoal, mas do bem comum), a abnegação (na repressão do amor erótico e da sexualidade e na morte como sacrifício último) e a fidelidade ao Partido (na exaltação partidária e nas elegias aos heróis tombados no combate) são algumas das temáticas encontradas na selecção de poemas de Andrade, que serão aqui discutidas à luz daquelas expostas por Cheng, Nechayev e Sinyavsky que tornam o Homem Novo o modelo a seguir.

A leitura destes poemas, focada na utilização do conceito de Homem Novo, revelou que este conceito não era desconhecido dos poetas nem dos partidos políticos da África de língua portuguesa alinhados com a ideologia marxista ${ }^{27}$. A título de exemplo, o conceito é abertamento evocado no poema da FRELIMO ${ }^{28}$, produzido de forma colectiva, "Forja do homem novo" (ANDRADE, 1980 , p. 48), datado de 1972, que evidencia o alinhamento político deste partido moçambicano. A utilização da palavra forja remete igualmente para "o dever militante de brandir o ferro no cimo dos montes" (ANDRADE, 1980, p. 13), uma referência que reporta para a literatura militante soviética onde a metáfora do ferro era utilizada para descrever a forja do Homem Novo ${ }^{29}$ (CHENG, 2009, p. 34). Para o colectivo de poetas da FRELIMO, é na luta que se formará o Homem Novo, o combate é a nova aprendizagem: "É esta a nossa universidade, a forja do homem novo,/da mulher livre, do militante fraterno, artesãos da nossa Pátria" (ANDRADE, 19080, p. 48). A luta é o processo criativo do artesão, do combatente. Cabe a ele criar a Pátria, essa é a sua missão, o seu propósito.

O guerrilheiro é o herói da Poesia de Combate. O seu heroísmo serve de modelo e de inspiração. Guiado pela revolução que trará liberdade, o guerrilheiro entoa o seu "Canto de Guerrilheiros" (Sérgio Vieira In ANDRADE, 1980, p. 89) "para que o povo viva/e o estado de guerra morra" (Ibidem). O poeta moçambicano Marcelino dos Santos, no seu poema "Segundo Panfleto" deixa claro o objectivo da luta, que é também o objectivo do guerrilheiro: o de não procurar a satisfação individualista, mas o bem comum. $\mathrm{O}$ sujeito do poema adverte: "O importante não é o que EU quero/o que TU queres/Mas o que NÓS queremos" (In ANDRADE, 1980, p. 100). A luta é pela pátria, pelo povo, conforme anuncia o poema do caboverdeano Abílio Duarte, "Marcha guerrilheira 'Venceremos", quando diz: "Lutemos sempre unidos pelo povo" (In ANDRADE, 1980, p. 31). Os guerrilheiros sacrificam-se pelas "verdades puras e revolucionárias,/tão belas e tão universais, [pelas quais] aceitam morrer/para que elas vivam" (Jorge Rebelo, "O mundo que te ofereço, amiga", In ANDRADE, 1980, p. 80). O guerrilheiro oferece, à sua amiga (conforme informa o título do poema) a sua vida por aquilo que acredita ser superior à sua própria vida: a revolução que exige o seu sacrifício. O guerrilheiro do poema de Rebelo demonstra a sua moralidade superior, característica do arquétipo Homem Novo, "moral concern for the other" (CHENG, 2009, p. 2002).

O seu heroísmo assenta não só na sua coragem e altruísmo, mas também na sua capacidade de abnegação, ciente que "o esforço que [faz]/não é leve nem pesado/É o que é necessário" (Marcelino dos Santos, "Segundo Panfleto", In ANDRADE, 1980, p. 103). Observa-se nesta Poesia de Combate, assim como na literatura revolucionária comunista russa e chinesa, a renúncia ao amor erótico, à sexualidade. O amor romântico é substituído pelo amor fraterno, pelo amor à liberdade. O sujeito poético do poema de Jorge Rebelo escreve à "Liberdade" como à sua amada, diz-lhe "Não te esqueças/que te amei sem 
desânimo" (In ANDRADE, 1980, p. 76). O angolano Nicolau Spencer em "Se nas tardes calmas..." (In ANDRADE, 1980, p. 59) escreve:

\author{
Não me perguntes amigo \\ os meus amores \\ os amores \\ as sendas trabalhosas persistentes - o \\ dever \\ os tranforma em Amor \\ Fecundidade de Vida \\ Alegria \\ e Liberdade
}

Os amores são agora outros e a fecundidade da sexualidade (fator de criação de nova vida) são substituídos pelo trabalho (revolucionário que trará a nova 'Vida') e pelo dever de o fazer, dever esse que o poeta evidencia em itálicos. Os amores são trocados por um só 'Amor', escrito com letra maiúscula para enfatizar a sua importância e grandeza: é Vida, Alegria e Liberdade.

O heroísmo do guerrilheiro leva-o à abnegação que ultrapassa a negação do amor carnal. A morte é o sacrifício maior, a abnegação da vida. O Homem Novo, guerrilheiro da luta de libertação, sabe: "Muitos não voltaremos [da luta]. Que importa?/ (...) a liberdade vale mais que a vida" (FRELIMO, "Irmão do Ocidente", In ANDRADE, 1980, p. 49). No grito da guerrilheira angolana Deolinda Rodrigues: "Vitória ou Morte!" ("Um quarto de Fevereiro", in ANDRADE, 1980, p. 58), ressoa o paradigma mais importante para o Homem Novo na Poesia de Combate: a renúncia da sua vida em prol da 'Vida' dos outros em 'Liberdade'.

O guerrilheiro, assim como o revolucionário de Nechayev, é um homem condenado, a "doomed man" (Apud CHENG, 2009: 18). Para o guerrilheiro do poema "Canção de despedida" de N'Fore Sambú, a morte na luta é uma possibilidade encarada com desafetação e sem lamúria, ele diz "Vou para Angola/Ouvirás dizer que já não vivo/Que ele morreu em Angola//De ti me despeço, pai/Adeus, adeus" (in ANDRADE, 1980, p. 38). A celebração do herói morto no decorrer da luta de libertação é a exaltação da abnegação suprema do guerrilheiro.

$\mathrm{Na}$ antologia de Andrade, foram identificados sete poemas dedicados a heróis combatentes que deram a vida pela revolução. Para Amílcar Cabral, revolucionário e teórico da descolonização, são dedicados cinco poemas nesta antologia. À são-tomense Alda do Espírito Santo, no seu poema "Requiem para Amílcar Cabral", chama-o de "Guevara de África / (...) Grande Líder/Da África Ocidental” (In ANDRADE, 1980, p. 163). Para o guineense Agnello Regalla, no seu poema "Camarada Cabral" (In ANDRADE, 1980, p. 165), Amílcar Cabral encerra em si o que este ensaio entende ser o modelo de Homem Novo, cuja dedicação serve de inspiração para a continuidade da luta:
As flores da nossa luta
Que tu com carinho plantaste, Estão a desabrochar
(...)
Serão sempre regadas
Com o nosso suor e sangue,
Serão sempre alimentadas
Pela força da nossa vontade.

A luta de Cabral norteia novos guerrilheiros: não só pela sua capacidade de liderança, mas pela sua postura guerrilheira que, aos olhos de Alda Lara, o iguala a Che Guevara. O poema de Abílio Duarte, dedicado ao guerrilheiro "Guerra Mendes" (versão portuguesa) (In ANDRADE, 1980, p. 30) é outro exemplo de como o modelo de Homem Novo, na vestes de guerrilheiro, manifesta-se na Poesia de Combate:
Verdadeiro guerrilheiro
Que lutou, lutou, lutou
Até ao fim da valentia
(...)
Com o peito varado de balas
Ainda se levantou para bradar: Independência,
Independência! À carga, camaradas!

Guerra Mendes é etendido como o 'verdadeiro' guerrilheiro: valente, lutador que, mesmo com o 'peito varado de balas' desafia a morte e incentiva os seus à luta. Entre os sete poemas dedicados aos heróis que morrem pela revolução, os poemas do angolano Pedro de Castro Van-Dunem, "Dois poemas para Hoji Ya Henda", em homenagem a este herói angolano morto na luta de libertação, 
são os que melhor exemplificam, de acordo com os parâmetros referenciados por Cheng e Sinyavsky, como o guerrilheiro reflete as características do arquétipo de Homem Novo, na Poesia de Combate das literaturas africanas em língua portuguesa. No poema "1-Juramento" (In ANDRADE, 1980, p. 118-119), o sujeito do poema lamenta:

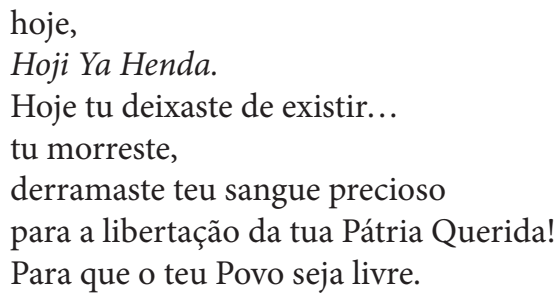

O herói morre tragicamente (tem o sangue derramado) pela libertação da pátria e fá-lo com amor 'pela pátria querida', por altruísmo, para que o 'Povo seja livre', fá-lo pelo outro. O herói deixou de existir fisicamente, mas continua vivo na memória daqueles a quem serve de inspiração para a luta:

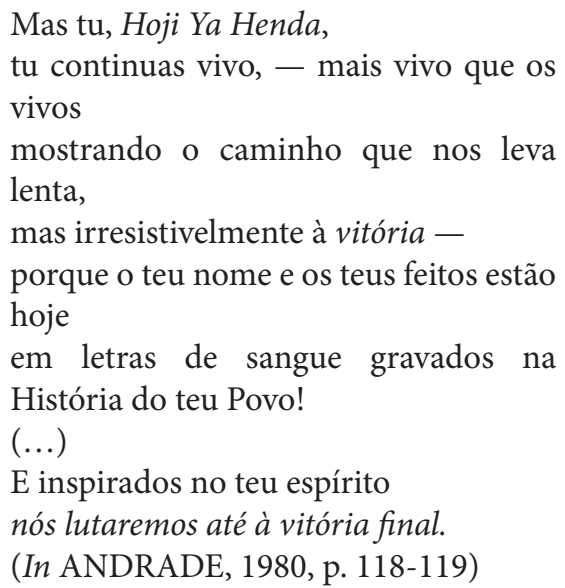

É o 'espírito' de abnegação do guerrilheiro, de entrega à luta pelo bem do Povo, que serve de inspiração para outros guerrilheiros. No poema "2 - Comandante Henda", Hoji Ya Henda continua sendo retratado como o um modelo a ser emulado:

Tu és pilar

da revolução

O teu heroísmo é para nós o grande exemplo

A tua coragem

E dedicação

Abre-nos a porta para a liberdade

Nós marcharemos, sim contigo!...

E com mais vigor ainda
Por estes campos regados do teu sangue

do teu sangue herói

e puro

nós marcharemos sim!...

(In ANDRADE, 1980, p. 120)

Estes poemas demonstram como o heroísmo e a abnegação, duas das características do Homem Novo Soviético, são incorporadas na figura do guerrilheiro que, no contexto da luta de libertação da África de língua portuguesa, toma corpo na figura do Homem Novo, que serve de modelo a ser seguido nesta revolução africana.

A conformidade ideológica, a devoção ao Partido e a lealdade política (CHENG, 2009, p. 220), estão igualmente presentes na antologia de Mário de Andrade, onde os respectivos partidos políticos são exaltados, assim como a ideologia socialista. O Partido faculta a ideologia e as armas para eliminar o colonialismo, conforme anuncia o poema de N’Fore Sambú "Não chorem, Pai e Mãe": "Nós somos vossos filhos do MPLA ${ }^{30} /(\ldots)$ Vamos expulsar Salazar com a PPCHA"31 (In ANDRADE, 1980, p. 35). Existem aqui duas possibilidades de leitura: a do filho tornado guerrilheiro que acalenta os seus pais dizendo-lhes que pertence a um movimento de libertação (MPLA) e que, com as suas armas, irá expulsar o regime colonial (representado pela figura de Salazar); ou a do guerrilheiro que acalenta um casal mais velho que encontra, provavelmente ao libertar alguma aldeia, dirigindo-se a eles como "mãe e pai", conforme é hábito respeitoso em alguns países africanos de língua portuguesa ao abordar uma pessoa mais velha. Desta maneira, as armas dos guerrilheiros são identificadas, perante a população, como armas de libertação e não como armas de subjulgação da tropa portuguesa. Os guerrilheiros se identificam como "filhos" do MPLA, entendendo filho como um produto ideológico, como partidário do MPLA. Em ambas possibilidades de leitura as armas, a ideologia e a força do Partido, são aliadas ao heroísmo dos guerrilheiros que irão "expulsar Salazar". No poema da FRELIMO "Somos combatentes da FRELIMO" (In ANDRADE, 1980, p. 46), a identificação partidária está clara tanto na autoria coletiva do poema, como no seu título. 
O propósito dos guerrilheiros é declarado: "somos instrumentos de um ideal" (Ibidem), a libertação. Contudo, é igualmente possível compreender o guerrilheiro, tornado Homem Novo, como instrumento paradigmático ideológico. $\mathrm{O}$ colonizado é transformado pela ideologia e pela identidade que abraça. Ao tornar-se combatente, torna-se num Homem Novo com um propósito nobre, que não é só seu, trata-se de um esforço coletivo, evidente na utilização do verbo ser na primeira pessoa do plural do presente indicativo. Ao afirmarem que são combatentes da FRELIMO, os sujeitos do poema proclamam a sua identificação com o coletivo do Partido, o que não só demonstra unidade ideológica, mas também lealdade e devoção ao Partido. Para a guerrilheira angolana Deolinda Rodrigues, indubitavelmente, será o Partido a trazer a "Vitória ao povo angolano/sob a bandeira do MPLA" ("Um quarto de Fevereiro", In ANDRADE, 1980, p. 57). Estes poemas exemplificam como o guerrilheiro dos poemas de combate selecionados por Andrade apresentam, para além da bravura, identificação e devoção ao Partido, características que Cheng aponta como fundamentais ao Homem Novo.

O conceito de Homem Novo surge na Rússia e, com a expansão do comunismo, é disseminado pelos países e pelos movimentos de libertação africanos que adotaram esta ideologia política. Cheng e Sinyavsky demonstram como o conceito de Homem Novo é desenvolvido na literatura e difundido através dela. O Homem Novo é o herói devoto da revolução, capaz de se autoanular pela revolução e pelo bem comum que esta trará, tornando-se no arquétipo a ser emulado pela nação.

Este ensaio observou como o conceito de Homem Novo manifestou-se na poesia préindependência das literaturas africanas em língua portuguesa, mais precisamente naquela que é comumente conhecida como Poesia de Combate, reunida na Antologia Temática de Poesia Africana II: O Canto Armado, organizada por Mário de
Andrade. De acordo com este antólogo, a poesia por si selecionada para esta antologia tem como tema central o herói libertador: o guerrilheiro.

Este ensaio demonstrou como o conceito de Homem Novo é desenvolvido na Poesia de Combate na figura do guerrilheiro. O guerrilheiro dos poemas selecionados por Mário de Andrade, analisados neste ensaio, apresentam as características conferidas por Cheng, Nechayev e Sinyavsky ao Homem Novo, com maior evidência para o heroísmo (impulsionado pelo seu sentido de missão e propósito), a abnegação (sendo a morte o sacrifício maior) e a fidelidade partidária. Nesta poesia o guerrilheiro incorpora e contextualiza os atributos do Homem Novo tornando-se no arquétipo para edificar sentimentos de pertença tanto partidária e ideológica como nacionalista, enquanto mobiliza o povo para unir-se aos movimentos populares para lutar pela libertação de suas terras. $\mathrm{O}$ chamamento para a luta assenta no sentimento de identidade, comunidade e propósito. O Homem Novo é trabalhado nesta poesia como modelo ideológico identitário de pertença à nação projetada pelo Partido. Está disposto a morrer pela nação projetada por este. Esta abnegação suprema, este sacrifício, confere-lhe um propósito moralmente superior. Fá-lo não por si mas por solidariedade e altruísmo, para servir a revolução que trará a 'Alegria' e a 'Liberdade' ao povo (c.f. Rebelo).

O Homem Novo da África de língua portuguesa surge para lutar pela libertação das suas terras, para construir a nação projetada no imaginário ideológico do Partido. Ele é o arquétipo de inspiração a ser emulado. A criação da nação depende da sua coragem, do seu sangue e da sua vida. Da sua morte surgirá a Vida, pois entende que a guerra que trava não é de destruição, mas de construção de uma nação em 'Liberdade' (c.f. Rebelo), que o leva o a celebrar: "Na nossa terra/ as balas começam a florir" ("Vem contar-me o teu destino irmão", Rebelo In ANDRADE, 1980, p. 78). 


\section{Notas}

\section{1 (ANDRADE, 1908, p. 156).}

2 "an alternative human model", esta, como todas as seguintes são traduções do autor deste ensaio.

3 Sugestão de leitura: LARANJEIRA (2005).

4 "fighting phase".

5 Sinyavsky busca as raízes para a concepção do conceito de Homem Novo no Cristianismo. Para este escritor russo, "a idéia e até mesmo o termo 'novo homem' não têm a sua origem na revolução, mas na religião. O cristianismo propõe ao seu fiel que expunja de si mesmo o 'homem antigo', em outras palavras, que ele se limpe de seus pecados e se torne, com a ajuda de Deus, num homem novo/ the idea and even the term 'new man' are not original with the revolution but with religion. Christianity proposes to the believer that he expunge the 'ancient man' from himself, in other words, that he cleanse himself of his sins and become, with God's help, a new man” (SINYAVSKY, 1990, p. 120).

6 " $\mathrm{i}] \mathrm{t}$ is not the consciousness of man that determines their existence, but on the contrary, their social existence determines their consciousness".

7 Esta ideia levou a que Marx tivesse interesse na educação como meio para remodelar a natureza humana, viabilizando a irradicação do "homem alienado" pelo "homem bem desenvolvido" (CHENG, 2009, p. 14).

8 "Everything from it, for it, and toward it".

9 "ideology into personality, transforming an individual into a new man".

10 O panfleto de Lenin, de 1902, "What is to be done?" reflete a influência que a novela de Chernyshevsky teve na sua escrita, sendo este, segundo Cheng, o autor mais citado na obra de Lenin (CHENG, 2009, p. 18).

11 "incompatibility between sexuality and political commitment".

12 "heroic characters seemed sexless".

13 "The revolutionary is a doomed man. He has no interests of his own, no affairs, no feelings, no attachments, no belongings, not even a name. Everything in him is absorbed by a single exclusive interest, a single thought, a single passion - the revolution".

14 "There is no life outside the revolution".

\section{5 "Let them all become Che".}

16 Self-denial, class awareness, political consciousness, faith in the revolution, rejection of personal comfort.

17 Purposefulness, high morality.
18 "a fanatical faith in the supreme goal; the ability to translate that faith into action; and a desire to strive not for one's own glory but for the general good. Ideally, these heroic feats should not have afforded the new man any personal success or profit and even should have remained anonymous."

19 O Homem Soviético criado em 1930, o construtor socialista, é mais tarde substituído por um modelo menos robusto, mais indicado para o novo desafio de industrialização do país.

20 "while supressing even abnegating their material needs and individual interests so that the state could control as many resources as it needed for its development".

21 Sugestão de leitura: MABEKO-TALI (2018).

22 "a transformation of people's mentality and attitude".

23 Sugestão de leitura: LUIS (2014).

24 "poetry of revolt".

25 During this phase a great many men and women who up till then would never have thought of producing a literary work, now that they find themselves in exceptional circumstances - in prison, with the Maquis, or on the eve of their execution - feel the need to speak to their nation, to compose the sentence which expresses the heart of the people, and to become the mouthpiece of a new reality in action.

26 A Poesia de Combate foi muitas vezes musicada para ser cantada e compreendida por uma população muitas vezes com fraco conhecimento da língua portuguesa.

27 Sugestão de leitura: LARA (2017).

28 A Frente de Libertação de Moçambique, foi fundada em 1962 como movimento nacionalista para a libertação de Moçambique do jugo colonial. A FRELIMO toma o poder depois da independência e governa o país, durante a guerra-civil como um estado unipartidário. A FRELIMO continua a governar Moçambique com a introdução de um sistema multipartidário em 1990, que trouxe o fim da guerra-civil.

29 Cheng faz alusão ao poema de Alex Gastev, de 1819, "We grow out of iron" (CHENG, 2009, p. 34).

30 A data de fundação do Movimento Popular de Libertação de Angola é controversa. Oficialmente este movimento nacionalista foi fundado em 1956, pela mão de Mário (Pinto) de Andrade, um dos seus fundaores e primeiro presidente. Depois da independência de Angola, o MPLA governa o país, durante a guerra-civil, como um estado unipartidário. Atualmente o MPLA continua a governar Angola com a introdução do sistema multipartidário em 1992, que pôs fim à guerra-civil.

31 "Arma automática de fabrico soviético": nota explicativa de Andrade. 


\section{Referências}

ANDRADE, Mário de (Org.). Antologia Temática de Poesia Africana II: O Canto Armado. 2a ed. Praia/Lisboa: Instituto Caboverdeano do Livro/Sá da Costa Editora, 1980.

CHENG, Yinghong. Creating the "New Man": from Enlightenment Ideals to Socialist Realities. Honolulu: University of Hawai'i Press, 2009.

FANON, Frantz. The Wretched of the Earth. Trans. Constance Farrington. New York: Grove Press, 1963.

LARA, Lúcio (Ed.). Um amplo movimento... Itinerário do MPLA através dos documentos e anotações de Lúcio Lara. Vol I (até Fev. 1961). 3ª Ed. Luanda: Associação Tchiweka de Documentação (ATD), 2017.
LARANJEIRA, Pires. A perspectiva da Literatura Africana de Guerrilha. Ensaios Afro-Literários. p. 146-217. Lisboa: Nova Imbondeiro, 2005.

LUIS, Solange M. E. M. Sagrada Esperança, protesto e revolta: Agostinho Neto e a tomada de consciência no acordar da literatura angolana. In: LARANJEIRA, Pires; ROCHA, Ana T., A noção de ser: textos escolhidos sobre a poesia de Agostinho Neto. p. 703-714. Porto. Luanda: Fundação Dr. António Agostinho Neto, 2014.

MABEKO-TALI, Jean-Michel. Guerrilhas e lutas sociais: o MPLA perante si próprio, 1960-1977. Lisboa: Mercado das Letras, 2018.

SINYAVSKY, Andrei. Soviet Civilization: A Cultural History. Trans. Joanne Turnbull \& Nikolai Formozov. New York: Arcade Publishing, 1988. 